\title{
Diagnóstico imuno-histoquímico de pitiose cutânea em equinos
}

\author{
Immunohistochemical diagnostic of cutaneous pythiosis in horses \\ Pedro Miguel Ocampos Pedroso ${ }^{1}$, Pedro Soares Bezerra Júnior ${ }^{1}$, Caroline Argenta Pescador ${ }^{1}$, \\ André Gustavo Cabrera Dalto ${ }^{1}$, Giovana Rosa da Costa ${ }^{1}$, Daniela Isabel Brayer Pereira ${ }^{2}$, \\ Janio Morais Santurio² \& David Driemeier ${ }^{1}$
}

\begin{abstract}
RESUMO
Descrevem-se cinco casos de pitiose cutânea em equinos enviados ao Laboratório de Patologia Veterinária da Universidade Federal do Rio Grande do Sul, Brasil. Microscopicamente focos necróticos circundados por infiltrados de eosinófilos, neutrófilos, macrófagos e abundante tecido conjuntivo fibroso foi observado. Filamentos de hifas esparsamente septadas foram identificadas no centro das áreas necróticas. Na coloração de prata metenamina de Grocott hifas septadas, ramificadas foram também observadas no interior dos focos de necrose. O diagnóstico de pitiose foi confirmado em todos os casos através do teste de imuno-histoquímica em cortes de tecido usando um anticorpo policlonal anti-Pythium insidiosum. Imuno-histoquímica em tecidos fixados em formalina podem ser úteis no diagnóstico de pitiose quando o material submetido não pode ser mais utilizado para cultivo.
\end{abstract}

Descritores: equino, Pythium insidiosum, pitiose, imuno-histoquímica.

\section{ABSTRACT}

This report describes five cases of equine cutaneos pythiosis submitted to the Veterinary Pathology Laboratory Universidade Federal do Rio Grande do Sul, Brazil. Microscopically necrotic foci surrounded by eosinophils, neutrophils, macrophages infiltrated and marked fibrosis were observed. Septated scattered hyphal filaments were also identified in the center of necrotic areas. In Gomori methenamine silver-stained sections septate hyphae were also observed within areas of necrosis. A diagnosis of Pythium insidiosum infection was confirmed in all cases by immunoperoxidase staining of tissue sections using a $P$. insidiosum polyclonal antibody. Immunohistochemical on formalin fixed material can be useful for diagnosis when materials submitted to culture are not more available.

Keywords: equine, Pythium insidiosum, pythiosis, immunohistochemistry.

${ }^{1}$ Setor de Patologia Veterinária (SPV), Departamento de Patologia Clínica Veterinária, Faculdade de Veterinária, Universidade Federal do Rio Grande do Sul (UFRGS), Porto Alegre, RS, Brasil. CORRESPONDÊNCIA: D. Driemeier [davetpat@ufrgs.br]. ${ }^{2}$ Departamento de Microbiologia, Laboratório de Pesquisas Micológicas (LAPEMI), Universidade Federal de Santa Maria (UFSM), Santa Maria, RS, Brasil. 


\section{INTRODUÇÃO}

A pitiose é uma enfermidade cosmopolita, de ocorrência em áreas temperadas, tropicais e subtropicais [12,13]. O agente causador pertence à Família Pythiaceae, do Gênero Pythium e à espécie P. insidiosum [13]. É uma doença que afeta a pele e subcutâneo de equinos [12], bovinos [14], ovinos [15], caninos [11] e humanos [1]. Embora em equinos a forma clínica mais comum seja a cutânea [13], caracterizada por lesões ulcerativas granulomatosas, formando grandes massas teciduais necróticas branco-amareladas semelhantes a "corais", chamadas de "Kunkers"[5,13], o agente também pode afetar o trato intestinal [3,7,9]. Microscopicamente, a lesão é caracterizada por áreas eosinofílicas de necrose constituídas principalmente de eosinófilos, em cuja periferia observam-se imagens negativas tubuliformes correspondentes às hifas de $P$. insidiosum. Circundando os "Kunkers", há infiltrado de eosinófilos, macrófagos, intensa proliferação de tecido fibrovascular e, ocasionalmente, células gigantes e reação de Splendore-Hoeppli [6]. Nos últimos anos, técnicas sorológicas como imunodifusão, ELISA e imuno-histoquímica e mais recentemente PCR têm contribuído para o diagnóstico de pitiose nos animais [13].

O objetivo deste trabalho é descrever os achados imuno-histoquímicos de cinco casos de pitiose em equinos diagnosticados no Setor de Patologia Veterinária da Universidade Federal do Rio Grande do Sul (SPV-UFRGS) utilizando um anticorpo primário policlonal anti-Pythium insidiosum produzido em coelho no Laboratório de Pesquisas Micológicas (LAPEMI) da Universidade Federal de Santa Maria (UFSM).

\section{MATERIAIS E MÉTODOS}

O material deste estudo foi obtido de quatro biópsias previamente fixadas em formol e uma necropsia de equinos submetidos ao SPV-UFRGS, no período de janeiro de 2000 a maio de 2006. Os dados gerais dos animais foram informados pelos veterinários requisitantes. Amostras obtidas na necropsia foram enviadas para o LAPEMI-UFSM, para cultivo e identificação. Todas as amostras destinadas a histopatologia foram fixadas em formol a $10 \%$, processadas rotineiramente para exame histopatológico, incluídas em parafina, cortadas a $5 \mu \mathrm{m}$ de espessura e coradas pela hematoxilinaeosina (HE) e coloração de Prata Metenamina de Grocott (GMS) [8].

Adicionalmente, fragmentos de tecidos cutâneos foram submetidos à técnica de imuno-histoquímica, conforme Guedes et al. [4], utilizando um anticorpo primário policlonal anti- $P$. insidiosum na diluição de 1:100 e incubados em estufa a $37^{\circ} \mathrm{C}$, durante uma hora. Foi utilizado o cromógeno vermelho. ${ }^{1}$ Foram inseridos controles positivos de $P$. insidiosum e como controle negativo foi incluído um caso de infecção por Conidiobolus spp., os controles foram confirmados com isolamento e identificação do agente na lesão. $\mathrm{O}$ anticorpo primário foi produzido em coelho através de uma única inoculação de 20.000 zoósporos de Pythium insidiosum via subcutânea sem a utilização de adjuvantes. Coletas de sangue, a cada 14 dias, foram realizadas e a quantificação dos anticorpos foi através da técnica de Elisa. O soro utilizado corresponde à coleta do $45^{\circ}$ dia, o qual apresentou uma densidade óptica (DO) de 0,281. A DO considerada positiva para coelhos é de 0,105.

\section{RESULTADOS}

O histórico clínico dos materiais enviados ao SPV foram escassos. Somente foi relatado a presença de nódulos com localização anatômica nos lábios (2/5), nas narinas (1/5), no membro anterior (1/5) e, em um caso a localização não foi informada.

Macroscopicamente, as amostras apresentavam tecido conjuntivo fibroso, juntamente com material necrótico de coloração amarelada que se desprendiam facilmente do tecido circunjacente ("Kunkers"). O exame histopatológico foi semelhante em todos os casos, sendo caracterizados por focos necróticos associados a imagens negativas tubuliformes de hifas fúngicas, circundados por infiltrado de eosinófilos, neutrófilos e macrófagos e abundante tecido conjuntivo fibroso. Em todos os casos analisados, na coloração de Grocott, as hifas foram evidenciadas nas áreas de necrose esparsamente septadas e ramificadas (Figura 1). No material enviado para cultura (caso número 5), P. insidiosum não foi cultivado.

Os cinco casos analisados foram positivos na imuno-histoquímica para Pythium insidiosum, sendo caracterizada pela visualização de estruturas ramificadas e septadas (Figura 2). O controle negativo de Conidiobolus spp. utilizado na imuno-histoquímica não apresentou reação cruzada quando incubado com anticorpo anti-P. insidiosum.

\section{DISCUSSÃO}

O diagnóstico de pitiose, no presente estudo, foi confirmado pela técnica de imuno-histoquímica, 




Figura 1. Hifas longitudinais de Pythium insidiosum com estruturas esparsamente septadas e ramificadas (seta) na coloração de Grocott (Obj.100).

através de marcação das estruturas semelhantes a hifas esparsamente septadas com anticorpo anti-Pythium insidiosum. Os achados macro e microscópicos foram semelhantes aos descritos na literatura [10,12].

Tradicionalmente, o diagnóstico da pitiose baseia-se nas características clínicas, histopatológicas e no isolamento e na identificação do agente [5]. A técnica de imuno-histoquímica [2] é um importante passo para identificação de $P$. insidiosum em amostras previamente fixadas em formol, possibilitando a visualização do agente juntamente com a lesão. Ao contrário do que já foi observado em outros estudos [10], no presente trabalho, todos os casos analisados foram positivos no teste imuno-histoquímico. A probabilidade de falso positivo na imuno-histoquímica é pequena, uma vez que as hifas de $P$. insidiosum apresentam moléculas antigênicas com epítopos específicos do Reino Chromista, que não são encontrados nas hifas dos fungos zigomicetos [10].

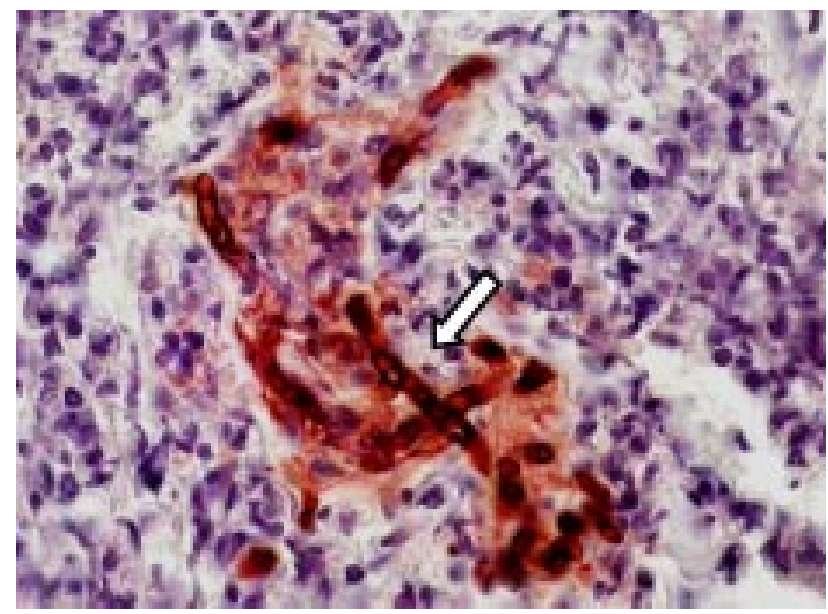

Figura 2. Marcação positiva em vermelho (seta) para Pythium insidiosum em imuno-histoquímica (Obj. 100).

\section{CONCLUSÕES}

Os achados anteriormente apresentados apontam que a técnica de imuno-histoquímica utilizando-se anticorpo primário policlonal anti- $P$. insidiosum produzido em coelhos pode ser uma ferramenta importante como método de diagnóstico em casos em que há suspeita de pitiose, especialmente em casos nos quais fragmentos de tecidos são submetidos ao laboratório fixados em formol $10 \%$ e em casos em que o isolamento não é obtido.

Agradecimentos. Ao professor Dr. Edson Moleta Colodel da Universidade Federal de Mato Grosso (UFMT) pelos controles positivos e negativos utilizados neste trabalho. À Coordenação de Aperfeiçoamento de Pessoal de Nível Superior (CAPES).

\section{NOTAS INFORMATIVAS}

${ }^{1}$ Vector Laboratórios, EUA.

\section{REFERÊNCIAS}

1 Bosco S.M.G., Bagagli E., Araújo Júnior J.P., Candeias J.M.G., Franco M.F., Marques M.E.A., Mendoza L., Camargo R.P. \& Marques S.A. 2005. Human Pythiosis, Brazil. Emerging Infectious Diseases.11: 715-718.

2 Brown C.C., McClure J.J., Triche P. \& Crowder C. 1988. Use of immunohistochemical methods for diagnosis of equine pythiosis. American Journal Veterinary Research. 49: 1866-1868.

3 Brown C.C. \& Roberts E.D. 1988. Intestinal pythiosis in a horse. Australian Veterinary Journal. 65: 88-89.

4 Guedes R.M.C., Gebhart C.J., Armbruster G.A. \& Roggow B.D. 2002. Comparison of different methods for diagnosis of porcine proliferative enteropath. Canadian Journal of Veterinary Research. 66: 99-107.

5 Leal A.T., Leal A.B.M., Flores E.F. \& Santurio J.M. 2001. Pitiose. Ciência Rural. 31: 735-743.

6 Meireles M.C.A., Riet-Correa F., Fischman O., Zambrano A.F., Zambrano M.S. \& Ribeiro G.A. 1993. Cutaneous pythiosis in horses from Brazil. Mycoses. 36: 139-142. 
Pedro P.M.O., Bezerra J. P.S., Pescador C.A., Dalto A.G.C., Costa G.R., Pereira D.I.B., Santurio J .M. \& Driemeier D. 2009.Diagnóstico imuno-histoquímico de pitiose cutânea em equinos.

7 Morton L.D., Morton D.G., Baker G.J. \& Gelberg. 1991. Chronic eosinophilic enteritis attributed to Pythium sp. in a horse. Veterinary Pathology. 28: 542-544.

8 Prophet E.B., Mills B., Arrington J.B. \& Sobin L.H. 1992. Laboratory Methods in Histotechnology. Washington: American Registry of Pathology, 279p.

9 Purcell K.L., Johnson P.J., Kreeger J.M. \& Wilson D.A. 1994. Jejunal obstruction caused by a Pythium insidiosum granuloma in a mare. Journal of the American Veterinary Medical Association. 205: 337-339.

10 Reis Júnior J.L. \& Nogueira R.H.G. 2002. Estudo anatomopatológico e imunoistoquímico da pitiose em eqüinos naturalmente infectados. Arquivo Brasileiro de Medicina Veterinária e Zootecnia. 54: 358-365.

11 Rivierre C., Laprie C., Guiard-Marigny O., Bergeaud P., Berthelemy M. \& Guillot J. 2005. Pythiosis in Africa. Emerging Infectious Diseases. 11: 479-481.

12 Sallis E.S.V., Pereira D.I.B. \& Raffi M.B. 2003. Pitiose cutânea em eqüinos: 14 casos. Ciência Rural. 33: 899-903.

13 Santurio J.M., Alves S.H., Pereira D.I.B. \& Argenta J.S. 2006. Pitiose: uma micose emergente. Acta Scientiae Veterinariae. 34: $1-14$.

14 Santurio J.M., Monteiro A.B., Leal A.T., Kommers G.D., Souza R.S. \& Catto J.B. 1998. Cutaneous Pythiosis insidiosi in calves from the Pantanal region of Brazil. Mycopathologia. 141: 123-125.

15 Tabosa I.M., Riet-Correa F., Nobre V.M.T., Azevedo E.O., Reis-Júnior J.L. \& Medeiros R.M. 2004. Outbreaks of Pythiosis in two flocks of sheep in Northeastern Brazil. Veterinary Pathology. 41: 412-415. 